\title{
El retorno a la tierra natal *
}

\author{
RHODA HENELDE ABECASSIS \\ Madrid
}

Quisiera empezar por agradecer a los directores de la revista Isegoría la oportunidad que me ofrecen para aportar mi testimonio personal en esta presentación. Lo considero un honor tratándose de un número dedicado a una reflexión en profundidad sobre la Shoah. A mí, sin embargo, más que de ideas, me toca hablar de hechos, y además de una vivencia muy concreta, la del retorno a mi tierra natal en el año que siguió al fin de la Segunda Guerra Mundial.

Me cuento entre quienes vivieron aquellos acontecimientos siendo niños muy pequeños, y que de adultos se sintieron muy reacios a contar su historia. Esto lo he sabido leyendo la revista de la Federation of Jewish Child Holocaust Survivors. Supongo que son muchas las razones de esta reticencia, pero destacaría dos de ellas:

1. Por considerar que nuestra historia, más que nuestra, pertenece a los mayores que consiguieron salvarnos, con gran coste para ellos y corriendo incontables riesgos.

2. También porque la mayoría de nosotros no pasamos por los campos de la muerte - nos quedamos con vida gracias a que logramos eludir la mano asesinay porque los relatos de quienes estuvieron próximos a las mortíferas duchas y a los hornos nos habían dejado enmudecidos.

¿Qué se puede decir después de oír el testimonio de alguien que llegó a bajar a los infiernos y volvió para contarlo?

No obstante, tras larga reflexión, he llegado a la conclusión de que aún queda algo por examinar y es el CÓMO se recibió a estos testigos de los infiernos tras su vuelta a la tierra.
Decía Jacques Stroumsa en su conferencia de la semana pasada que los supervivientes pensaban que al dar su testimonio, el mundo quedaría asombrado, sobrecogido y, sin embargo, descubrieron que todo se sabía y se aceptaba. También esperaban los que salían de los campos, y de otros escondrijos, como en nuestro caso, que el mundo los acogería con comprensión, tal vez con compasión y calor humano, tras conocer lo que habían pasado. Mal podían imaginar que, antes de permitirles esa vuelta a la tierra, aún se les sometería a un duro y prolongado purgatorio. $\mathrm{La}$ experiencia de ese purgatorio la viví a una edad, todavía infantil pero ya suficientemente madura, como para recordarla y relatarla.

No se puede hablar del primer año de la posguerra sin tener como telón de fondo y punto de referencia el magistral libro de Primo Levi, La Tregua. Nadie como este gran escritor y perspicaz observador ha sabido retratar el desconcierto, el caos, los controles superpuestos, de la malherida Europa de entonces. Sin embargo, con todo, su caso fue excepcional.

Menos se habla de lo ocurrido a la masa de judíos polacos que también regresaron a su tierra natal donde no les esperaba un hogar, difícilmente un pariente vivo y menos aún un entorno receptivo.

Nosotros regresamos a Polonia dentro de aquel grupo que, como mis padres cuando me llevaron a mí de bebé, consiguió huir de la Polonia ocupada por los nazis cruzando clandestinamente la frontera rusa. Los rusos, al descubrirnos en un bosque de las afueras de la ciudad bielorrusa de Gómel, nos deportaron a Siberia. Mi padre se alistó en el ejército rojo, en parte 
porque había militado en el partido comunista de Polonia, pero sobre todo para tratar de que la deportación a Siberia de mi madre y mía se hiciera en condiciones algo más soportables. Pero todo el capítulo siberiano es historia aparte y queda para otras ocasiones.

Al terminar la guerra, los rusos metieron a sus refugiados polacos en trenes de ganado y en esas condiciones, entonces yo ya era una niña de seis a siete años, hicimos durante varios días nuestro viaje de vuelta como «repatriados» a Polonia.

\section{Zgozhelitse}

El tren nos dejó en la ciudad de Zgozhelitse. Nos bajamos y comenzamos a andar por una ciudad bombardeada y semidesierta. Al pasar delante de algún edificio de los que habían quedado en pie, los recién llegados entraban y simplemente los iban ocupando. Recuerdo que mi madre y yo entramos con un grupo a una casa de varias plantas, subimos por unas escaleras de madera y, mientras los demás se quedaban en los pisos bajos, nosotros seguimos hasta el desván y abrimos la puerta a una habitación completamente amueblada, que me pareció un palacio.

No tardamos en saber que esta ciudad antes se llamaba Görlitz, en la Baja Silesia, y había estado habitada por una población alemana que, al acabar la guerra, huyó con lo puesto.

En aquella casa se respiraba un aire de normalidad, de alivio por el final de una larga pesadilla, y de libertad. Nuestra actividad principal en los días siguientes fue la exploración de casas abandonadas y la búsqueda entre los escombros. A los niños hasta se nos dejó andar solos por aquella desierta ciudad y lo pasamos muy bien abriendo cajones, disfrazándonos con la ropa de los armarios y luego trayendo a nuestras madres toda clase de cachivaches y hasta grandes fajos de dinero, que luego sólo sirvió para que jugáramos con él, ya que habían cambiado la moneda.

Aquellos primeros días los recuerdo como los más divertidos de mi infancia, pero la diversión duró sólo eso, unos días. Entre los escombros pronto no aparecían más que ladrillos. El vacío empezó a llenarse de población polaca. También en aquellos días notamos en las calles la presencia de judíos cuyo aspecto físico nos estremecía. Se nos aclaró que en las afueras de Görlitz los alemanes habían montado un campo de concentración. No todos los que salieron liberados de allí eran judíos, pues años más tarde descubrí que el gran compositor francés Olivier Messaien, un ferviente católico por otra parte, también fue liberado del mismo campo por aquellas fechas.

Pronto nuestra situación cambió. Corrió la voz de que bandas de jóvenes polacos apaleaban a todos los judíos que encontraban a su paso. Ya no volvimos a salir a la calle y en aquella bonita casa se nos instalaron de nuevo el miedo, el hambre y la desesperación. Cogidos en aquella trampa, la pregunta que se planteaban nuestros vecinos y correligionarios unos a otros, ¿qué hacer ahora?, no encontraba respuesta.

Una noche recibimos la visita de unos hombres que, hablándonos en yiddish, nos apremiaron a vestirnos y recoger nuestros bártulos. Prometían llevarnos a un lugar más seguro. Les obedecimos y salimos andando en la oscuridad hacia un edificio grande, que en su día habría sido algún edificio público, tal vez un hospital, donde ya estaban reunidos muchos de los judíos de la ciudad. A aquellos hombres los llamamos «los brigadistas», pues eran los judíos palestinos a quienes Churchill permitió formar una brigada, The Jewish Brigade que luchó contra los nazis bajo bandera británica. Al terminar la guerra habían recibido órdenes de la Agencia Judía, presidida entonces por David Ben Gurión, para permanecer en Europa y ayu- 
dar a los supervivientes. En aquel momento, y en otros más adelante, su ayuda fue providencial y no sé lo que habríamos hecho sin ellos.

\section{Los Brigadistas y el Kibbutz}

Aquel edificio se convirtió en una fortaleza de la cual ya no volvimos a salir a las calles de Görlitz. El modo de vida allí fue organizado según el modelo de kibbutz que funcionaba en Palestina, es decir, la vida en comuna, con división del trabajo, aunque éste no pudiera ser agrícola como en la versión original. Los niños jugamos en un jardín detrás de la cocina, donde podía ver trabajar a mi madre, y para dormir nos asignaron una habitación aparte, al estilo de lo habitual en la realidad del kibbutz. Supongo que debo avergonzarme al admitirlo, pero no pasé ni una noche en la llamada «Casa de los niños», pues me escapaba cada noche para estar con mi madre. Los niños de la guerra estábamos muy apegados a nuestras madres, después de pasar unidos tantos avatares. A pesar de ello, como luego contaré, se nos impuso la separación.

Del episodio del kibbutz destacan en mi memoria dos sucesos. Al principio, mi madre me llevó con ella para hablar con los Brigadistas. Quiso pedirles que nos ayudaran a llegar a su pueblo natal, Constantinow, región de Biale Podlaska. Deseaba indagar qué había sido de sus padres y, ¿quién sabe?, si algún familiar aún vivía allí. «¿Volver?», le dijeron. «Imposible. Les matarán. Creerán que viene a reclamar su casa paterna, y les matarán. Ya han empezado a llegarnos noticias de asesinatos de supervivientes por este motivo. En cuanto a sus padres, todos los judíos de aquella zona fueron deportados a Treblinka.» Yo no sabía entonces lo que significaba Treblinka y recuerdo que sentí vergüenza cuando vi a mi madre llorar tan desconsoladamente delante de aquellos extraños. Más tarde, pues no tardé en averiguarlo, supe que aquel campo de exterminio se encontraba a mitad de camino entre Constantinow, el shtetl de mi familia materna, una familia de judíos devotos, jasidim, y Varsovia, lugar de procedencia de mi familia paterna, judíos ilustrados, librepensadores y con hijos, incluyendo a mi padre, universitarios, y en cuyo gueto vivieron una vez casados mis padres y yo vine al mundo. Ambas familias terminaron en Treblinka.

El segundo suceso del que guardo un recuerdo imborrable fue la celebración de la primera cena de Pascua, el Séder Pésaj, durante la cual se relata la salida del pueblo de Israel de Egipto y el paso de la esclavitud a la libertad. Fue la primera vez que me topé con la idea de que ser judío era algo más que ser la parshívaya zhidovka, como me llamaban los niños, y no sólo niños en Rusia, sino que incluía una historia de libertad y de orgullo colectivo.

Poco después mi madre me anunció que iba a empezar nuestra fuga de Polonia hacia un lugar seguro. El viaje iba a ser corto, pero peligroso. Tenía que ser clandestino ya que salimos de donde salimos sin papeles de ninguna clase y las fronteras de toda Europa estaban cerradas. Además, era necesario que nos separásemos, pues los niños viajarían en condiciones algo mejores que los adultos. Era esto o arriesgarnos a permanecer en Polonia, y la alternativa estaba clara.

\section{El Viaje}

El «corto» viaje duró nada menos que casi un año. Desde aquella Pascua primaveral hasta llegar a la primera capital que recuerdo, una Praga blanca, cubierta de nieve, pasamos por muchas peripecias. Nos llevaron en camionetas militares cubiertas de lona y casi siempre de noche. Nuestras paradas, que a veces duraban días o semanas, se hacían en lugares aislados en las 
montañas o en casas abandonadas en pueblos o ciudades, de las cuales nunca salíamos al exterior. Pasamos los días limpiando estos sitios, recogiendo tras nuestras comidas y lavando nuestras mudas. Todos nuestros movimientos eran sigilosos, con mucha disciplina y mucho miedo. Sólo en Praga vimos la luz del día. El paso por la frontera era legal. Nos hicieron bajarnos de las camionetas y nos pusieron en una larga cola. Los policías nos cachearon rápidamente uno a uno, preguntándonos: «¿Tabaco? ¿Alcohol?» Muertos de miedo, decíamos que no. A algunos niños de pronto les dio un ataque de risa. No sé si fue por la tensión, o por las cosquillas o por la estupidez de la pregunta, pero la risa prendió como una mecha y recorrió toda la cola, y mirando ansiosos a los policías, descubrimos aliviados que también sonreían. En Praga, donde pasamos unas semanas, nos alojaron en un edificio grande, con camas literas, tal vez un cuartel militar, y hasta se nos permitió jugar en la nieve. Bueno, no a todos. Los que, como hice yo, agarramos las sempiternas anginas nos quedamos en la cama.

La segunda capital que recuerdo fue Viena. Nos hacía ilusión verla después de que nos hablaron tanto de ella. Nuestras camionetas llegaron de noche y atravesamos el centro de la ciudad. Lo sé porque, aunque la lona nos encerraba por completo, pudimos oír las voces de la gente y el ruido de los coches. Pero la camioneta se detuvo en una calle oscura y rápidamente nos bajaron al sótano de un gran edificio, seguramente público. Aún en la oscuridad, oíamos los ruiditos de las ratas, y al encender la luz, no recuerdo si eléctrica o de velas, las vimos realmente pasar corriendo de un lado para otro. Nos mandaron sacar nuestras mantas militares y que nos fuéramos a dormir envueltos en ellas en el suelo de aquel sótano vacío. Nos envolvimos en las mantas pero nos negamos a tumbarnos, - un pequeño motín - por miedo a las ratas. Pero poco a poco el cansancio hizo que terminásemos durmiendo en aquel suelo, tan mal acompañados, y no sólo esa noche sino durante dos semanas enteras. En todo ese tiempo los niños que sólo éramos medio huérfanos no parábamos de preguntar por nuestras madres, pero la respuesta fue siempre que en aquel desbarajuste no era posible averiguar la trayectoria de los adultos.

\section{El lugar seguro}

Finalmente llegamos al anhelado lugar seguro y salimos de nuestra clandestinidad. Nos hallábamos, luego lo supe, en la zona americana de la Alemania ocupada. Y allí nos metieron en unos campos que no sé como calificarlos. Oficialmente los llamaban «D. P. (Displaced Persons) Camps», un nombre eufemístico, ya que no éramos desplazados de nuestra tierra natal, sino huidos de ella, y en nuestro caso dos veces huidos. Duraron cinco años, hasta 1950, y yo pasé casi cuatro años de mi infancia en cuatro de ellos.

\section{El reencuentro}

El primero al que llegamos se encontraba en la ciudad de Kassel. Yo ya estaba convencida de que nunca volvería a ver a mi madre y que, si ella me encontrase, no me reconocería con mis cambios de dentadura. Pero mi madre, que llegó al campo de Ulm, desoyendo lo que le decían, no se resignaba tan fácilmente. Tal como ella lo contaba, y ésta es en realidad su historia, ya había perdido a su marido y a un hijo en Siberia, a toda su familia en Polonia y no iba a permitir que se le perdiera la única persona a quien consiguió sacar adelante, y encima cuando ya había terminado la guerra.

Entre muchos recogieron el dinero suficiente para su desplazamiento a Munich donde se encontraban las oficinas de la 
American Joint Distribution Committee y la Agencia Judía. Allí lo único que pudieron hacer por ella fue darle una lista de campos donde llegaban transportes de niños y algo de dinero para el viaje y su manutención. Con la lista en la mano mi madre recorrió campo tras campo, y miraba a todas las niñas en busca de la suya. Cuando se le iban acabando los medios, volvía a Munich por otra lista de transportes infantiles y más dinero para su búsqueda.

Un mediodía en Kassel, mientras caminábamos los niños en fila de dos hacia un comedor, oí a alguien gritando mi nombre en yiddish, como me llamaba sólo ella. Al verla corriendo hacia mí, hice lo que más teníamos prohibido, rompí filas y corrí hacia ella. Cuando dejó de machacarme, pude ver que todos los niños habían roto filas y nos rodearon, compartiendo mi alegría. Un buen grupo de transeúntes alemanes también se había parado a mirarnos y también sonreían. En aquellos tiempos todos entendían el significado de un reencuentro. Mi madre me llevó con ella a su campo en Ulm (un cuartel militar, el de Ludendorff Caserne, Neu-Ulm D. P.) donde esperaba conocerme mi padrastro. Los Campos también constituyen un capítulo aparte, pero quisiera describir brevemente el ambiente que allí se respiraba.

\section{Los «D. P. Camps»}

En estos campos ya no pasamos ni hambre ni miedo, pero eran vallados y con guardias militares en la entrada. A menudo pregunté a mi madre el porqué de las vallas, ya que la guerra había terminado. La respuesta, que no me la pudo dar ella ni yo conseguía imaginármela, me llegó hace unos años en un documental que pasaron en la Televisión Española (y que volvieron a pasar hace poco). Los norteamericanos nos encerraron porque temían la venganza judía contra los alemanes, una revuelta destructiva. La idea me estremeció, pues no por allí iban nuestros pensamientos.

En mi memoria, el encierro no fue lo peor de esos campos, ni lo fueron las infrahumanas condiciones sanitarias. Lo más doloroso de los campos eran las noches. No se podía dormir. Eran sitios diáfanos, a veces, como en Kassel, grandes naves con filas de catres militares, y se oía todo. Así pues, o te despertaban los sollozos, o los gritos de alguna pesadilla, o una voz relatando los horrores que había vivido, o discusiones, peleas, recriminaciones, voces de la desesperación.

En realidad, el verdadero testimonio ocular de mi generación es el del terrible sufrimiento que dejaron tras sí los perpetradores de aquella densa concentración de dolor. Desgraciadamente, las palabras quedan cortas para describirlo.

A medida que transcurrían los años en aquellos campos, fuimos tomando conciencia de nuestra situación, o tal vez yo crecí y comencé a entenderla. Llegamos allí llevando cada uno su propio dolor, sus pérdidas y sus aflicciones individuales. Después, conviviendo tan estrechamente, pudimos percibir claramente la magnitud de nuestra tragedia, la enormidad de nuestra pérdida, la total destrucción del mundo que conocíamos.

Por otra parte, podíamos observar a través de las vallas cómo alrededor del campo la gente volvía a su vida normal, el país de nuestros verdugos estaba siendo reconstruido, disfrutando de cuantiosas ayudas económicas y de libertad. A nosotros, mientras tanto, como si hubiésemos sido los malhechores, se nos mantenía encerrados en inmundos campos, sin tener adónde ir, los países de Europa negándose a acogernos y América acogiendo a unos pocos y a duras penas. Era imposible no sacar la conclusión de que, de alguna manera, en Europa estaba pesando el no saber qué hacer con los remanentes de aquella «Solución Final» que no llegó a serlo. 
Ante tanta injusticia se produjo en nosotros una reacción colectiva, una gradual toma de postura. Su expresión no fue lanzarnos a destruir todo lo alemán (como temía el General Patton al encerrarnos), sino empeñarnos en frustrar su vil proyecto. Fue ésta la actitud popular en la cual el filósofo Emil Fackenheim basó su escueto y elocuente mandamiento. No darás a Hitler una victoria póstuma:

1. A los que buscaban nuestra muerte, les responderíamos viviendo (apenas hubo suicidios en los campos y sí, según el documental, la tasa de natalidad más alta de toda Europa).

2. A los que querían un mundo sin judíos, les responderíamos asegurando nuestra continuidad como tales, resucitando nuestro viejo idioma común.

3. A los que contaban con nuestra indefensión para servirles de chivo, aprenderíamos a defendernos.

4. A los que deseaban nuestra exclusión de la raza humana, lucharíamos para ser incluidos como una nación más entre las naciones del mundo.
Aunque ahora podría sonar como discurso político, aquél fue nuestro sentir visceral, primordial, anterior a la política, anterior al nacionalismo. Fue por ello que aquella gente estuvo dispuesta a subir en esos viejos y sobrecargados barcos, enfrentándose a la marina británica, para volver a Israel, la tierra en la que sus ancestros dejaron su huella y a la que colectivamente nunca dejaron de sentirse unidos. Se ha dicho y repetido que el Estado de Israel no existiría sin el Holocausto. Mucho habría que hablar de ello, pero lo que verdaderamente importa, aquí y ahora, es que el Holocausto como tal no habría existido si Israel hubiese nacido veinte años antes.

Para terminar, los testigos necesitan hacerse oír por quienes, como están haciendo ustedes ahora, se proponen reflexionar con seriedad y en profundidad sobre los hechos del pasado, para que puedan ser los nuevos «avisadores del fuego» contra los pirómanos del futuro, y por ello les estaré siempre agradecida.

* Este texto fue leído en la presentación del número 23 de Isegoría, dedicado al Holocausto, que tuvo lugar en la Residencia de Estudiantes el 20 de junio de 2001. 